\title{
Utopie et Engagement
}

\begin{abstract}
Nadine Ltaif
Two contradictory pulls, an impossible choice, a double imperative. The utopian, turning her back on society, finds freedom on the margins, escaping the judgement of others. The engagée opens a dialogue with these others. Writing the occasional text on Algeria, she denounces what she sees. Lacking the courage to sustain a utopian existence. Or, risking emergence from behind the barrier erected as a defense against disillusionment.

She lives in an era of harsh indifference. Finally, like Diogenes, finds the courage to pursue happiness in her own way. Fleeing from corruption and from those who give way to power. This kind of courage is a form of engagement, the most intransigent.
\end{abstract}

Deux demandes simultanées : de deux sources différentes. Deux textes : un sur l'Utopie, l'autre sur l'Engagement. Deux routes opposées. L'Utopique décide de s'engager dans les deux routes à la fois.

Quand elle tourne le dos à la société, l'Utopique se crée un espace libéré de la corruption. Dans la marge, elle trouve sa liberté, hors du jugement d'autrui. Par contre en s'engageant, elle s'adresse. Elle ouvre le dialogue avec l'opposant, celui qui ne partage pas sa pensée, ou qui la juge. Par ailleurs, en s'assumant entièrement, elle accepte son épanouissement personnel sans chercher l'approbation de ses pairs. Au risque de vivre en marge de la pensée courante, ou de ceux qui n'attendent que reconnaissance et honneurs. Parfois dans l'urgence, il lui arrive d'écrire un poème ou un texte pour l'Algérie, car une main doit être tendue, même maladroitement. Un regard pour dénoncer ce qu'il voit : le crime. Filmer, donner la parole. Elle tentera de sortir de sa marge, qui n'est qu'une marque de survie, une barrière érigée contre la vanité du monde. Une brèche dans le mur de la désillusion. Et à travers la fêlure, elle cherchera à vivre l'exigence du geste direct envers l'opprimé. Pour tenter de l'aider, de le défendre. 
Vivre 1'Utopie de la marge est une exigence.

Vivre $1^{\prime}$ Engagement en est une double.

Car parfois, ce courage manque.

Trop de pouvoir ont poussé l'Utopique au découragement.

Le Pouvoir en soi a fini par la dégoûter tout à fait de tout effort fourni pour le combattre.

Elle vivra une ère d'indifférence effroyable, et de dureté, où l'accomplissement de soi est sans pitié pour l'autre. Et où toute quête du Bonheur sera devenue quête risible, tant sera devenue lointaine la notion même de bonheur. Et pourtant. Lorsque l'Utopique tel le cynique Diogène aura le courage de dire à Alexandre "Ôte-toi de mon soleil." Et que la seule Quête encore viable restera la quête du Bonheur. Au risque de faire rire les plus sceptiques. Nous comprendrons ceux et surtout celles qui fuient loin, loin de la corruption, pour fuir, fuir ceux et celles qui rampent devant le pouvoir et devant la société. Ce courage-là est aussi un engagement, le plus exigeant sans doute. Le plus intransigeant. 